\title{
Procesos transicionales y violencia política: la continuidad de la lucha armada de ETA (1977-1982)
}

\author{
Mariano García de las Heras González \\ UNIVERSIDAD COMPLUTENSE DE MADRID, ESPAÑA \\ mgarciadelasheras@ucm.es
}

Resumen: El artículo cuestiona la imagen mitificada del proceso democratizador inaugurado en España tras la experiencia del régimen franquista y subraya el componente de la violencia política desplegada en los escenarios de incertidumbre que presiden los contextos transicionales. La estructura del texto asume una división dual motivada por la reflexión teórica y el estudio analítico de un caso concreto vinculado con el fenómeno del terrorismo. El soporte teórico aporta una caracterización generalizada de los procesos de transición democrática y detalla la manifestación de la violencia política en el marco de la cuestión territorial vasca. En el terreno empírico, el análisis recae en la estrategia prolongada de la lucha armada de ETA en la coyuntura articulada por la aprobación del Estatuto de Autonomía en el año 1979 y profundiza en la valoración de una serie de hipótesis: por un lado, la debilidad representativa de la candidatura de Herri Batasuna frente a la consolidación hegemónica de un nacionalismo moderado; y por otro, la solidez organizativa respaldada por la configuración de una comunidad legitimadora en torno al discurso radicalizado del independentismo vasco.

Palabras clave: violencia política, transición, terrorismo, Estatuto, País Vasco, ETA

Abstract: This paper disputes the mythologized image of the democratizing process opened up in Spain after the experience of the Franco's regime and stresses the component of political violence deployed in the scene of uncertainty that preside over the transitional contexts. The structure of the text assumes a dual division motivated by theoretical reflection and the analytical study of a concrete case linked to the phenomenon of terrorism. The theoretical support provides a general characterization of the processes of democratic transition and details the manifestation of political violence within the framework of the Basque territorial question. In the empirical field, the analysis falls on the prolonged strategy of ETA's armed struggle in the conjuncture articulated by the approval of the Statute of Autonomy in the 1979 year and goes deeper into the valuation of a series of hypotheses: on the one hand, the representative weakness of the Herri Batasuna's candidature against the hegemonic consolidation of a moderate nationalism; and on the other, the organizational solidity backed by the configuration of a legitimating community around the radicalized discourse of the Basque independence movement

Keywords: political violence, transition, terrorism, Statute, Basque Country, ETA

\footnotetext{
* El autor agradece las sugerencias y observaciones iniciales de Henar Criado, profesora del Departamento de Ciencia Política y de la Administración, y las valiosas aportaciones de las personas que participaron en el proceso de evaluación
} 


\section{Introducción: incertidumbre y violencia política en procesos transicionales}

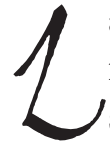

a imagen mitificada de la transición española y su curso aparentemente pacífico admiten contestaciones desmarcadas de los enfoques funcionalistas ${ }^{1}$, que subrayan la transformación política a partir de un examen centrado en el desarrollo institucional -marco jurídico, participación electoral, sistema de partidos- y valoran el cambio sin prestar atención a las numerosas contradicciones y los múltiples actores subyacentes. De este modo, "la transición representa el fin del ciclo de las violencias contemporáneas y la superación del mito de las dos Españas" (Baby, 2018: 27). El interés del estudio de la democracia radica en el examen de una serie de transformaciones porque el sistema democrático "es un particular sistema de procesamiento y resolución de conflictos intergrupales" (Przeworski, 1988: 93).

Los incipientes dispositivos democráticos conviven en España con elementos sustantivos derivados del orden político franquista. Esta pervivencia cuestiona, e incluso contradice, la legalidad del sistema democrático durante los primeros compases de la transición y esta particularidad propicia, junto con la incertidumbre inherente a los fenómenos de cambio político, el posible surgimiento de unos ciclos de violencia dirigidos hacia la desestabilización de los procedimientos democratizadores. En este sentido conviene destacar el contraste entre la idea de una democracia conceptualizada como un sistema de reglas abiertas - "incertidumbre organizada"- y el transcurso de la democratización, que alude al acto de someter todos los intereses a la competencia - "incertidumbre institucionalizada"- (Przeworski, 1991: 13-14).

Los procesos de transición democratizadora están compuestos de distintas fases y uno de los principales obstáculos reside en la dificultad para identificar previamente a los agentes del cambio. Una solución analítica consiste en establecer una clasificación en función de los intereses que presumiblemente defienden los distintos grupos involucrados en una situación conflictiva, mientras que otro enfoque permite elaborar una discriminación directa de los actores según sus posicionamientos estratégicos.

La desintegración de un modelo autoritario exige la organización de alguna alternativa con opciones reales para los individuos excluidos (Przeworski, 1988: 87-88). Las iniciativas violentas de ETA ejemplifican, no obstante, la coexistencia de propuestas contradictorias y planteamientos alternativos al diseño democrático introducido por las elites que presiden el proceso transicional en España. El incremento exponencial de las acciones armadas representa un objeto de estudio interesante para

1. Algunos ejemplos de ello son las publicaciones que reivindican la importancia de los diferentes movimientos sociales en el proceso de democratización (Pérez Ledesma, 1994; Laraña, 1999) o el papel de la violencia desde los últimos compases de la dictadura (Soto, 2005; Baby, 2018) 
calibrar los ritmos democratizadores en un contexto definido por un elevado grado de violencia y unos compases iniciales motivados por los escenarios de incertidumbre política.

La incertidumbre y la violencia son dos coordenadas implícitas en los procesos de transición política. El marco teórico de este trabajo reflexiona sobre la relación de ambos elementos para profundizar en el caso específico de la implantación de un sistema democrático en España, generalmente presentado como un modelo de referencia bajo la imagen idealizada del consenso, y la consideración del fenómeno de la lucha armada capitalizada por la organización ETA.

El clima de incertidumbre proporciona un rasgo sobresaliente a los procesos de cambio en la escena política, ya que las reglas del juego son constantemente negociadas por los diversos actores implicados y esta característica articula del devenir político mediante flujos permanentes. Esta dinámica expresa un arduo objeto de contienda porque las agencias participantes en una democracia luchan por satisfacer sus intereses inmediatos y/o aquellos que afirman representar.

La disputa persigue concretar las normas y procedimientos que perfilan el futuro sistema político, mientras que la configuración de estas pautas designa a los perdedores y vencedores de la contienda política dentro de un marco legal que limita los recursos aplicables de manera legítima en la escena pública e identifica a los actores susceptibles de participar en dicho espacio.

En el caso concreto de España, el proceso de transición democrática es calificado de paradigmático en el contexto de la denominada "tercera ola democratizadora" (Huntington, 1994). Los analistas coinciden en destacar, desde un primer instante, la ejemplaridad de unas elites heterogéneas que logran sellar un consenso político desmarcado de conflictividades y potencialmente exportable a otras latitudes (Linz, 1993; Pridham, 1995).

Sánchez-Cuenca y Aguilar (2009) elaboran una tipología de la violencia ajustada al contexto de la transición política española. En primer lugar, la violencia independentista guiada por una concepción radical del nacionalismo y el propósito de disociar determinados territorios en la relación centro-periferia. En segundo término, la violencia revolucionaria ubicada en el espectro ideológico de la izquierda, cuyas acciones pretenden impulsar una insurrección popular contra el sistema político. Por último, la violencia ejercida por los grupos de derecha filofascista, que manifiesta una reacción contra el nuevo ordenamiento democrático y un ataque orientado hacia las organizaciones que reivindican propuestas centrífugas.

La problemática de la violencia está originada en la carencia de otros instrumentos para colmar ciertas perspectivas. Aróstegui (1994) añade que el recurso a la coerción desde el poder oficial está efectivamente dirigida hacia el mantenimiento 
de un sistema estable de expectativas ${ }^{2}$, mientras que el la utilización de la violencia por instancias ajenas al aparato estatal funciona como respuesta a la distribución de dichas expectativas. En estos términos, muchos teóricos soslayan la influencia de las diferentes ideologías, creencias y percepciones que incitan al odio, pero que resultan fundamentales en la instigación de determinados conflictos políticos (Wilkinson, 1986; Drake, 1998; Hoffman, 2010).

La violencia política constituye un desafío crítico en el marco transicional español y, especialmente durante los primeros años, la lucha armada de ETA representa una firme amenaza (Coverdale, 1979). El incremento de sus acciones esconde una cierta complejidad, sobre todo a partir de finales del año 1977, y el caso particular de España proporciona un ejemplo muy sustantivo de estudio porque es, junto con Irlanda del Norte, el país que ha registrado unas cifras más elevadas de violencia política en Europa durante un período de paz.

En el caso concreto del nacionalismo vasco radical, la percepción de la violencia equivale a un instrumento para lograr aquello que es interpretado como una liberación y que coincide, además, con el destino nacional de Euskadi. La práctica de ETA constituye una tipología de la violencia política ejercida por una organización que pretende la independencia o el grado de autodeterminación y, por tanto, su acción está orientada hacia el poder establecido (Letamendía, 1997: 91). Asimismo, la lucha armada exhibe un sólido afianzamiento en el imaginario de ETA tras el fallecimiento de Franco y los dirigentes de la organización subliman la violencia porque consideran que es una fuente creadora de la identidad colectiva nacionalista (Douglass y Zulaika, 1990; Baby, 2018: 223).

En el País Vasco, el programa estratégico de ETA es el resultado de la particular lectura realizada por el grupo armado de la transición de la dictadura franquista hacia la implantación de un sistema democrático parlamentario. Este proceso no cumple con las expectativas del nacionalismo radical y los planteamientos tácticos de ruptura con el franquismo mantienen unas aspiraciones invariables, que coinciden con un análisis doble: por un lado, la definición de la transición como un escenario de continuidad del régimen de Franco y, por otro, la consideración de aceptar la alternativa representada por KAS como respuesta al fin del franquismo (Letamendía, 1997: 305).

2. La violencia ejercida por el aparato estatal entronca con la existencia de dos fuentes indiferentes a su grado democrático: aquellas prácticas resultantes de la exclusión social y la represión emanada de la construcción del llamado estado-nación. La coerción estatal tiene un sustrato social y una cartografía territorial, que permanece distanciada tanto del centro político como de la cúspide de la jerarquía social y, por este motivo, los grupos más sujetos a la violencia monopolizada por el estado son aquellos que están conectados mediante una condición socioeconómica desfavorable y una marcada territorialidad periférica (Letamendía, 1997: 224) 
El carácter instrumentalizado de la violencia responde a una lógica racional, que implica un ajuste entre los recursos y los objetivos perseguidos. En este sentido, el terrorismo coincide con una racionalidad colectiva y su actor principal es una organización política radical con una serie de preferencias o valores que apuesta por el despliegue de actividades armadas en el transcurso de su acción (Crenshaw, 1981, 1987, 1994). En términos operativos destaca la utilización de procedimientos sistemáticos para elaborar una selección intencional en la toma de decisiones de los grupos terroristas y esta pauta permite anticipar, de un modo consciente, "las consecuencias de los diferentes cursos de acción o inacción” (Crenshaw, 1994: 18). El siguiente epígrafe está dedicado, precisamente, al examen de los cálculos efectuados por ETA a través de las diversas disquisiciones que aborda la organización desde el tramo final de la dictadura hasta la coyuntura política del Estatuto de Autonomía.

\section{Dilemas estratégicos de ETA y hegemonía del nacionalismo moderado}

ETA es una organización que practica una violencia guiada por la premisa de lograr unos determinados objetivos políticos y su lucha armada constituye un recurso para alcanzar una meta específica: la independencia de Euskadi. Por el contrario, el transcurso del cambio político pretende garantizar, de manera simultánea, la nacionalización del aparato estatal. La respuesta a estas contradicciones consiste en la construcción de unos repertorios cargados de connotaciones simbólicas y la primera referencia es la aprobación del texto constitucional en 1978 (Gurrutxaga, 2005: 142). De hecho, las reivindicaciones del nacionalismo periférico son un punto cardinal en la configuración territorial del estado plural en el modelo democrático español.

La singularidad del caso vasco reside en la participación de dos agentes principales que capitalizan la movilización nacionalista y asumen dos vías divergentes: por un lado, la senda institucional representada por el Partido Nacionalista Vasco (PNV) y, por otro, la apuesta por la lucha armada desarrollada por ETA. Ahora bien, esta organización experimenta una serie de fragmentaciones condicionadas por el dinamismo de la escena política, tanto a escala global como a nivel estatal.

El Proceso de Burgos constituye un punto de inflexión histórico porque surge en el momento más crítico de su trayectoria, e incluso los indicios para su disolución son apreciables (Jáuregui, 2006: 254). Este primer hito significa la "auténtica refundación simbólica” de ETA (Aranzadi, 1994: 202), ya que el resultado de este episodio proporciona una derrota moral y política al régimen franquista porque los acusados logran convertir el juicio en una condena de la dictadura mediante la descripción de las torturas infligidas por la policía (Sullivan, 1988: 114-115). El suceso provoca el nacimiento de una nueva generación de militantes antifranquistas en Euskadi y de 
una ETA militarista renovada, que adquiere su consolidación tras el atentado perpetrado contra Carrero Blanco el 20 de diciembre de 1973 (Jáuregui, 2006: 254).

Las tesis maoístas de la denominada guerra revolucionaria dominan la reflexión teórica inicial de la organización y mantiene una vigencia práctica hasta 1978. La base de esta estrategia responde a la fórmula de la espiral de violencia concretada en el ciclo acción-represión-acción y su principal propósito consiste en desencadenar una insurrección popular que permita doblegar a las fuerzas represoras estatales mediante la acción insurgente ${ }^{3}$. En cambio, las dinámicas observadas en un escenario internacional definido por la Revolución de los Claveles en Portugal y el derrumbamiento formal de la llamada Dictadura de los Coroneles en Grecia ejercen, junto con la multiplicación de los síntomas que anuncian el debilitamiento de la dictadura ${ }^{4}$, una influencia sustantiva en la lectura analítica que elabora ETA.

La organización inicia una campaña de acciones armadas sin precedentes y esta tendencia provoca el distanciamiento de la mayor parte de la oposición democrática, cuyas expectativas residen en un desmantelamiento progresivo de la dictadura y el comienzo de una transición gradual dirigida hacia la implantación de una democracia parlamentaria (Sullivan, 1988: 176-177). ETA analiza la coyuntura política y los debates internos provocan disensiones en el seno de la organización ante el reiterado dilema de compaginar la lucha armada con la movilización de masas.

Las constantes discrepancias en la dirección de ETA desembocan en una escisión sustantiva registrada en octubre de 1974 y que determina el rumbo de la organización. La fractura escenificada expresa la constitución de dos vertientes: por un lado, el sector político-militar que defiende la actividad conjunta entre la movilización y la lucha armada bajo las siglas ETApm; y, por otro, la fracción militar desplazada a la clandestinidad que sostiene la necesidad de privilegiar exclusivamente la lucha armada bajo la firma de ETAm (Baby, 2018: 219; Letamendía, 1997: 261).

La rama político-militar despliega una intensa actividad armada en los meses inmediatamente posteriores. Su actividad genera una fuerte represión entre sus filas y provoca el desmantelamiento de muchos de sus comandos, mientras que ETAm reafirma sus posiciones porque, como expresa en su Agiri o Manifiesto publicado en noviembre de 1974, "no están puestas las bases que harían posible una insurrección" (Letamendía, 2011: 88).

3. En este sentido, El fracaso de las pretensiones insurreccionales de un movimiento calificado de revolucionario deriva en el fenómeno terrorista que adoptan muchas organizaciones, según Unzueta (1997: 17). Una segunda línea interpretativa argumenta que, por el contrario, ETA "asegura la continuidad inmutable de sus procedimientos y de sus objetivos, con independencia de la voluntad de sus miembros" (Domínguez, 1998: 90)

4. Los indicadores que muestran el agotamiento del franquismo son numerosos y es posible destacar, además del deterioro del estado de salud de Franco, el creciente vigor de las movilizaciones sociales o la configuración de diversas coaliciones de oposición como, por ejemplo, la creación de la Junta Democrática en julio de 1974. 
La represión estatal adquiere matices arbitrarios y muestra un carácter generalizado que concentra la participación de los distintos cuerpos coercitivos, como la Guardia Civil o la Brigada Político-Social. Un elemento importante es la organización de grupos calificados de paralelos a las fuerzas de seguridad y orden público, cuya actuación permanece impune y que cobra un papel muy relevante en las tácticas represoras estatal a largo alcance (Bruni, 1988: 228).

La estrategia basada en la secuencia acción-represión-acción significa un desafío aceptado por el Gobierno de Madrid y su objetivo consiste en imprimir un salto cualitativo en la práctica represiva (Bruni, 1988: 228). En los primeros años de la década de 1970, ETA permanece impregnada de un carácter radical y utópico que refleja nuevas versiones nacionalistas resultantes de dos corrientes ideológicas: los movimientos armados que luchan por la emancipación colonial -Cuba, Argelia, Vietnam- y la retórica revolucionaria procedentes del marxismo-leninismo (Letamendía, 1997: 264).

La fracción militar organiza unas fuerzas con una enorme experiencia y una disciplina castrense, que permiten adaptar sus estrategias a la lucha armada (Jáuregui, 2006: 262). En este escenario resulta imprescindible la absorción de numerosos miembros procedentes del sector político-militar mayoritario que ocasionan, junto a la represión citada anteriormente, un debilitamiento de ETApm que progresa paulatinamente hacia su disolución. Además, ETAm no sufre los costes tan elevados de la coerción estatal debido a su condición clandestina. Los rigores impuestos por la clandestinidad son suavizados en los llamados "santuarios", que la organización utiliza como bases de retirada. En el caso específico de ETA, la localización de estos territorios coincide con algunas poblaciones francesas fronterizas y su desactivación comienza con el inicio de las actividades del GAL en Iparralde.

Las discrepancias internas registradas entre los años 1973-1974 sobre las propuestas estratégicas de lucha y sus correspondientes limitaciones concluyen con el triunfo de la vía armada encarnada por ETAm, que determina el abandono de la movilización de masas y el llamamiento a las bases nacionalistas para su propia organización. En esta atmósfera nace la Koordinadora Abertzale Sozialista (KAS), que asume el papel de bloque dirigente y cuyo surgimiento está asociado formalmente con la VII Asamblea celebrada en septiembre de 1976.

El distanciamiento entre las opciones políticas adquiere su máxima visibilidad en la coyuntura del Estatuto de Autonomía. El PNV interpreta este hito como una fase inscrita en la secuencia que conduce a la autodeterminación del pueblo vasco a

5. Este término designa aquellos territorios situados en estados limítrofes en los que existe una cierta tolerancia hacia los militantes del grupo armado (Letamendía, 1997: 311) 
través de un ciclo reformista. Por el contrario, ETA mantiene firme su compromiso con la apuesta insurreccional mediante la instrumentalización de la violencia y sus iniciativas armadas experimentan un incremento sustantivo, especialmente contrastado a partir de la progresiva desmovilización nacionalista.

El descenso de los niveles de protesta está estimulado por una serie de reformas democratizadoras que logran disminuir las reivindicaciones sociopolíticas, mediante la aprobación de la Ley de Amnistía, y las demandas económicas, con los célebres Pactos de la Moncloa firmados en último tramo del año 1977. Por consiguiente, la reducción del grado de incertidumbre originado tras la desarticulación del franquismo y la consolidación paulatina del proyecto democrático relevan las expectativas independentistas a un plano muy secundario. La violencia política ejercida por ETA obedece a la inviabilidad de cumplir con sus objetivos en un corto plazo y plantea la posibilidad de abrir una vía negociadora promovida por la intensidad de sus acciones armadas.

Los índices de mayor letalidad corresponden a ETA y, en este escenario, el dilema gravita en torno a la continuidad de la lucha armada tras los resultados relativos a la consulta sobre el proyecto autonómico celebrado el 25 de octubre de 1979. Una primera línea explicativa reside en la propia organización, pues ETA comienza el proceso transicional segmentada en dos ramificaciones que consideran la necesidad de recurrir a presupuestos antagónicos. La apuesta militar es inicialmente minoritaria, pero las sucesivas adhesiones invierten el peso numérico de ambas fracciones y aumentan, por tanto, la capacidad de ETAm para lanzar su gran ofensiva en el marco diseñado para la elaboración del texto constitucional.

Un segundo razonamiento que contribuye a comprender la prolongación del ciclo de violencia desarrollado por ETA responde a la movilización social conectada con las tesis independentistas en mayor o menor medida (Sánchez-Cuenca y Aguilar, 2009: 444). Los recursos movilizados de manera espontánea no exigen una intensa campaña violenta por parte del grupo armado porque, de lo contrario, sus efectos provocarían un resultado contraproducente. Esta correspondencia entre la movilización y los ciclos de violencia es inversamente proporcional porque, como apuntan Sánchez-Cuenca y Aguilar (2009: 431), las expresiones violentas pretenden ocupar el vacío provocado por el desfallecimiento de las acciones colectivas.

La hegemonía iniciada por el nacionalismo moderado del PNV trunca las mínimas opciones valoradas por los sectores de ETA partidarios de competir en las instituciones parlamentarias ${ }^{6}$. Los resultados de las primeras elecciones generales demo-

6. El PNV expresa su hegemonía desde los inicios del proceso de institucionalización autonómica vasca y converge, desde 1985, con el socialismo estatal en una actitud contraria a la violencia desarrollada por ETA. El máximo ejemplo de esta sincronía es la firma del Pacto de Ajuria Enea en 1988 (Letamendía, 1997: 262) 
cráticas celebradas tras la dictadura franquista en junio de 1977 muestran un primer indicio del insuficiente apoyo electoral obtenido por las opciones rupturistas. El análisis de la debilidad representativa mostrada por la candidatura de HB en las sucesivas jornadas electorales de 1979 y 1982 frente a la preferencia destacada del PNV requiere una breve reflexión sobre el escenario político vasco.

El paisaje político de Euskadi es el resultado de unas circunstancias que añaden numerosos matices en la evolución del comportamiento electoral de la sociedad vasca durante la primera fase de la transición democrática en el conjunto de España. Estas singularidades expresan un doble condicionamiento: por un lado, las dificultades exógenas provocadas por un contexto internacional definido por la crisis económica y las resistencias proporcionadas por el centralismo estatal manifestadas a través de una sistemática represión; y, por otro lado, los obstáculos endógenos propiciados por la estructura económica industrial específica, la confrontación de identidades derivada de la construcción de repertorios simbólicos heterogéneos y la agudización del ciclo de violencia política (Llera, 1984: 172)

El comportamiento electoral de la sociedad vasca contempla la pugna política de numerosos partidos que logran una representación parlamentaria en la escala autonómica y, por tanto, estas formaciones son relevantes para la gobernabilidad del País Vasco. La fragmentación parlamentaria indica el grado de competitividad del sistema y, en el caso de las elecciones celebradas en 1979, este indicador muestra una diferencia porcentual entre las dos primeras formaciones que supera el $8 \%$ del total de los votos válidos ${ }^{7}$. La participación electoral de la ciudadanía vasca muestra una sincronía con el comportamiento del electorado en el conjunto del Estado y está situada entre el 77-78\% del total censado, pero el predominio nacionalista moderado del PNV compite en un sistema de partidos con un elevado grado de polarización ideológica.

Un rasgo particularmente significativo del sistema de partidos en el País Vasco es su profundo pluralismo polarizado, que adquiere visibilidad en dos direcciones combinadas: el tradicional eje compuesto por la dualidad ideológica izquierda/derecha y la diferenciación entre las distintas fuerzas políticas en función de las connotaciones nacionalistas. Esta segunda vertiente responde a nuestra hipótesis porque las tres candidaturas nacionalistas - PNV, HB y EE- logran superar el 50\% del total de los sufragios del electorado vasco en las elecciones generales celebradas en 1979 y 1982 (Gráfico 1), pero más de la mitad de ese porcentaje procede del electorado que apuesta por el PNV en ambas citas con las urnas. El ligero incremento de la concen-

7. La política vasca está condicionada por la compleja articulación institucional propiciada por la condición foral, la fragmentación de su sistema de partidos, la polarización ideológica aportada por el componente nacionalista y la existencia de un movimiento que legitima la violencia terrorista (Llera, 1998: 414). 
tración del voto nacionalista está motivado por la preferencia de una candidatura moderada.

\section{Gráfico 1.}

Concentración comparada del voto nacionalista (1979-1982)

1979

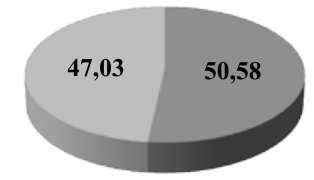

Nacionalistas $\square$ No nacionalistas
1982

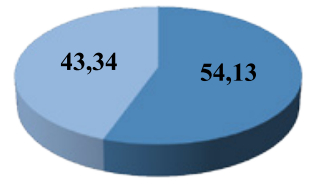

Nacionalistas $\square$ No nacionalistas

Fuente: elaboración propia a partir de los datos del Ministerio del Interior

Una segunda línea de reflexión enlaza con la armonía entre los objetivos del grupo armado y la formación política $\mathrm{HB}^{8}$, que participa en un juego electoral democrático que impugna el objetivo cardinal del nacionalismo radical vasco: la independencia. Sin embargo, HB decide renunciar a los posibles escaños obtenidos tras la celebración de la jornada electoral de 1979 y ETAm interpreta los comicios como una oportunidad para cuantificar las adhesiones más directas (Fernández, 2013: 352; Fernández y López, 2012: 134). ETA pretende calibrar sus fuerzas a través del electorado vasco y busca una justificación legitimadora para sus objetivos políticos, pero la fragmentación política del País Vasco está determinada por la territorialidad porque cada provincia define un subsistema o una correlación de fuerzas particular y relativamente distanciada del panorama autonómico en su conjunto (Llera, 1998: 427-428).

En las elecciones generales de 1979 (Tabla 1), el electorado de Guipúzcoa y Vizcaya apuesta decididamente por el PNV, que logra alzarse como la formación con un mayor porcentaje de los votos en comparación con la segunda fuerza política más votada, el PSOE-PSE. En estas circunscripciones, la escuadra nacionalista supera al grupo socialista por una horquilla que oscila entre los 8-10 puntos porcentuales en Guipúzcoa y Vizcaya, respectivamente. Sin embargo, el electorado alavés opta por 
la candidatura de UCD, que logra concentrar el $25^{\prime} 41 \%$ de los votos válidos y relega al PNV a la segunda posición con un $22^{\prime} 92 \%$, mientras que las candidaturas nacionalistas en Álava apenas alcanzan un 37'53\% de los sufragios. El mejor resultado de la candidatura de HB corresponde al 17'59\% de los votos logrados en Guipúzcoa y esta cifra mantiene una diferencia inferior a un punto con respecto a los resultados logrados por el PSOE-PSE en dicha provincia. En Vizcaya, la formación batasuna no consigue superar el $15^{\prime} 98 \%$ logrado por UCD y el nacionalismo radical vasco es la cuarta fuerza política con un 14'51\% entre el electorado vizcaíno. El nacionalismo moderado alcanza un 27 '57\% del total de los votos para sumar siete actas en el Congreso, mientras que HB consigue captar el 14'99\% del electorado vasco y lograr tres escaños.

Tabla 1

Elecciones generales al Congreso, 1-III-1979 (\% votos válidos)

\begin{tabular}{l|c|c|c|c|c}
\hline Candidatura & País Vasco & Álava & Guipúzcoa & Vizcaya & España \\
\hline PNV & $27^{\prime} 57$ & $22^{\prime} 92$ & $26^{\prime} 50$ & $29^{\prime} 18$ & $1^{\prime} 65$ \\
\hline PSE-PSOE & $19^{\prime} 05$ & $21^{\prime} 35$ & $18^{\prime} 21$ & $19^{\prime} 06$ & $30^{\prime} 40$ \\
\hline UCD & $16^{\prime} 88$ & $25^{\prime} 41$ & $15^{\prime} 38$ & $15^{\prime} 98$ & $34^{\prime} 84$ \\
\hline HB & $14^{\prime} 99$ & $9^{\prime} 94$ & $17^{\prime} 59$ & $14^{\prime} 51$ & $0^{\prime} 96$ \\
\hline EE & $8^{\prime} 02$ & $4^{\prime} 67$ & $12^{\prime} 87$ & $5^{\prime} 85$ & $0^{\prime} 48$ \\
\hline PCE-EPK & $4^{\prime} 59$ & $3^{\prime} 33$ & $3^{\prime} 05$ & $5^{\prime} 77$ & $10^{\prime} 77$ \\
\hline UFV & - & $6^{\prime} 18$ & $1^{\prime} 04$ & $4^{\prime} 24$ & $5^{\prime} 89$ \\
\hline Participación & $65^{\prime} 95$ & $68^{\prime} 85$ & $66^{\prime} 01$ & $65^{\prime} 33$ & $68^{\prime} 04$ \\
\hline Abstención & $34^{\prime} 05$ & $31^{\prime} 15$ & $33^{\prime} 99$ & $34^{\prime} 67$ & $31^{\prime} 96$ \\
\hline \hline
\end{tabular}

Fuente: elaboración propia a partir de los datos del Ministerio del Interior

El análisis de la orientación del voto en las elecciones generales celebradas en 1982 (Tabla 2) resulta significativo en comparación con los antecedentes electorales: la candidatura moderada del PNV incrementa su porcentaje de votos válidos hasta alcanzar el $31^{\prime} 73 \%$ del total de los sufragios, mientras que los resultados obtenidos por HB y EE indican una estabilidad. El estudio de las preferencias políticas en las diferentes circunscripciones del País Vasco advierte nuevamente de una similitud entre el electorado guipuzcoano y vizcaíno, que opta por la candidatura del PNV y convierte 
la opción del nacionalismo moderado en una apuesta hegemónica. En cambio, los votantes alaveses inclinan su apuesta electoral por la formación socialista, que logra una diferencia del 13'38\% en comparación con la segunda fuerza política. La candidatura de HB registra sus mejores resultados en Guipúzcoa, ya que logra concentrar el 19'29\% de los sufragios y el componente nacionalista agregado en esta provincia asciende hasta el $61^{\prime} 81 \%$ de los votos. Este porcentaje contrasta significativamente con el 38 ' $85 \%$ del voto nacionalista conseguido en Álava, aunque en el conjunto del País Vasco logra sumar un 54'13\% del total de los votantes que acuden a las urnas.

Tabla 2

Elecciones generales al Congreso, 28-X-1982 (\% votos válidos)

\begin{tabular}{l|c|c|c|c|c}
\hline Candidatura & País Vasco & Álava & Guipúzcoa & Vizcaya & España \\
\hline PNV & $31^{\prime} 73$ & $21^{\prime} 95$ & $32^{\prime} 60$ & $33^{\prime} 38$ & $1^{\prime} 88$ \\
\hline PSE-PSOE & $29^{\prime} 16$ & $35^{\prime} 33$ & $29^{\prime} 99$ & $29^{\prime} 64$ & $48^{\prime} 11$ \\
\hline HB & $14^{\prime} 71$ & $9^{\prime} 94$ & $19^{\prime} 29$ & $13^{\prime} 11$ & 1 \\
\hline AP-PDP-PDL & $11^{\prime} 64$ & $19^{\prime} 13$ & $8^{\prime} 14$ & $12^{\prime} 02$ & $26^{\prime} 36$ \\
\hline EE & $7^{\prime} 69$ & $6^{\prime} 96$ & $9^{\prime} 92$ & $6^{\prime} 56$ & $0^{\prime} 48$ \\
\hline CDS & $1^{\prime} 83$ & $3^{\prime} 83$ & $1^{\prime} 67$ & $1^{\prime} 48$ & $2^{\prime} 87$ \\
\hline PCE-EPK & $1^{\prime} 75$ & $1^{\prime} 08$ & $1^{\prime} 26$ & $2^{\prime} 19$ & $4^{\prime} 02$ \\
\hline Participación & $79^{\prime} 34$ & $81^{\prime} 83$ & $78^{\prime} 12$ & $79^{\prime} 52$ & $79^{\prime} 97$ \\
\hline Abstención & $20^{\prime} 66$ & $18^{\prime} 17$ & $21^{\prime} 88$ & $20^{\prime} 48$ & $20^{\prime} 03$ \\
\hline \hline
\end{tabular}

Fuente: elaboración propia a partir de los datos del Ministerio del Interior

El comportamiento electoral de la sociedad vasca en 1982 evidencia el estancamiento de $\mathrm{HB}$ en esta jornada electoral porque su condición de tercera fuerza política autonómica responde a la desaparición de UCD como candidatura única y a la disminución de votos experimentada en Vizcaya en comparación con los resultados alcanzados en la convocatoria anterior. Además, HB pierde un acta parlamentaria en favor del nacionalismo moderado, que incrementa su representación desde los siete diputados elegidos en la legislatura anterior hasta los ocho escaños conseguidos en 1982.

El análisis de los resultados correspondientes a las elecciones generales de 1979 y 1982 muestra la debilidad electoral de HB, mientras que el nacionalismo moderado 
representado por el PNV adquiere la condición de partido predominante en el sistema de partidos del País Vasco. Los efectos de la ofensiva violenta protagonizada por ETA tras la aprobación del Estatuto de Gernika no se traducen en un incremento de votos, sino que su apuesta parlamentaria experimenta un estancamiento que debilita la vía parlamentaria. Sin embargo, la nacionalista logra aumentar ligeramente el porcentaje agregado de votos procedente de las diferentes candidaturas defensoras del nacionalismo vasco en cuatro puntos con respecto a las elecciones celebradas en marzo de 1979, pero esta tendencia responde a la hegemonía electoral que consolida al PNV como primera fuerza política en Euskadi. En consecuencia, ETA comprueba la desafección del electorado vasco por sus reivindicaciones políticas a través de la lucha armada en los resultados que obtiene $\mathrm{HB}$ en las sucesivas convocatorias electorales de 1979 y 1982, mientras contempla el progresivo predominio de la apuesta nacionalista moderada representada por el PNV. En definitiva, el balance relativo a estos comicios generales evidencia el progresivo desfallecimiento de la vía parlamentaria, que transcurre en paralelo a la consolidación democrática del sistema político español.

\section{Comunidad legitimadora: adhesiones, comandos, secuestros y apoyo social}

Durante la época franquista, la subordinación de las nacionalidades históricas provoca una animadversión hacia la autoridad que representa Madrid y coadyuva, simultáneamente, en la consolidación y propagación de un sentimiento de identidad colectiva distintivo en tales regiones. Esta actitud centrífuga ocasiona el apoyo pasivo o activo que amplios sectores de la sociedad vasca brindan a las iniciativas violentas de ETA durante la última década de la dictadura (Maravall y Santamaría, 1989: 135). En los primeros años de la transición, las grandes movilizaciones de masas crean un terreno fértil para ETA y el número de adhesiones experimenta un continuo incremento. ETAm dinamiza la creación de su propia comunidad de legitimación (Letamendía, 1997: 261).

Los constantes estados de excepción decretados en el País Vasco son una buena muestra del permanente hostigamiento policial desde 1968 hasta pocos meses antes del fallecimiento de Franco. Esta excepcionalidad explica la formación de una nueva comunidad nacionalista anti-represiva que establece una nueva relación de identidad entre los símbolos diferenciadores de la población vasca -euskera, ikurriña, himnosy la democracia (Letamendía, 1997: 263). Sin embargo, la oposición antifranquista española apuesta por la reforma pactada con las oligarquías procedentes de la dictadura y esta determinación implica la inviabilidad de satisfacer los proyectos políticos generados en el seno del nacionalismo radical (Letamendía, 1997: 264).

El binomio formado por el grupo armado y la comunidad de legitimación persigue unos objetivos marcados por la impronta nacionalista a través de una estrate- 
gia compartida y mediante unos recursos específicos movilizados por el principio de elección racional, aunque sometidos a los rigores impuestos por la condición de clandestinidad (Crenshaw, 1983; Della Porta, 1996). Los medios movilizados por el grupo armado para conseguir sus objetivos son: organización, exclusividad o no en el uso de la lucha armada, atentados, grupos sociales legitimadores y ordenación política (Letamendía, 1997: 310).

La adhesión es un indicador significativo que permite calibrar la magnitud de la capacidad de maniobra de ETA durante los años estudiados. El Proceso de Burgos representa la fecha inicial para el análisis detallado de la actividad armada en la organización a partir de la distribución anual del ingreso de un total de 1.013 miembros entre los años 1971-1992.

Las cifras del Gráfico 2 muestran una primera tendencia progresivamente creciente y acelerada desde el final de la dictadura franquista, que culmina con la incorporación de 139 personas en el año 1978. La adhesión de un tercio del total de los datos recopilados por Domínguez (1998: 33) coincide con el binomio 1977-1979. Al mismo tiempo, esta concurrencia admite la explicación motivada por la desmovilización ocasionada tras la aprobación de la Ley de Amnistía y la celebración del referéndum sobre el Estatuto de Autonomía del País Vasco, además de la admisión de los bereziak procedentes de ETApm en la primavera de 1977 y que consideran irreconciliable la participación política institucional con la lucha armada. El principal objetivo consiste en frenar el avance visible de unos cauces institucionales que determinen el rumbo político en Euskadi.

El contexto de liberalización del régimen franquista experimenta una convergencia con el aumento de los promotores de la violencia de ETA y las claves que explican este comportamiento remiten a un doble razonamiento. En primer lugar, la apertura del sistema política que pretende instalar un modelo democrático orientado hacia la institución de unas garantías que permitan el desarrollo de una serie de libertades y derechos. En segundo término, la incertidumbre que acompaña generalmente a este tipo de procesos incita a una mayor implicación política, que se traduce de manera correlativa en un mayor grado de participación y movilización activa.

Las ideas señaladas enlazan con la segunda tendencia expresada en el gráfico anterior a través de la significativa disminución que muestran los datos relativos al ingreso en ETA a partir de la década de 1980. No obstante, este repliegue también responde a la eficacia de los cuerpos de seguridad estatal resultante de distintos mecanismos de modernización y a la política específica en la lucha contra el terrorismo que implementan, de un modo coordinado, los gobiernos español y francés. La tendencia decreciente manifiesta implícitamente los efectos de la consolidación democrática tras una serie de episodios significativos: el intento golpista abortado 
en febrero de 1981, el cambio político generado por la mayoría absoluta lograda por los socialistas en los comicios de 1982 y las citadas iniciativas contrainsurgentes que sortean, en diferentes ocasiones, la legalidad.

\section{Gráfico 2}

Distribución anual del ingreso de activistas en ETA (1971-1992)

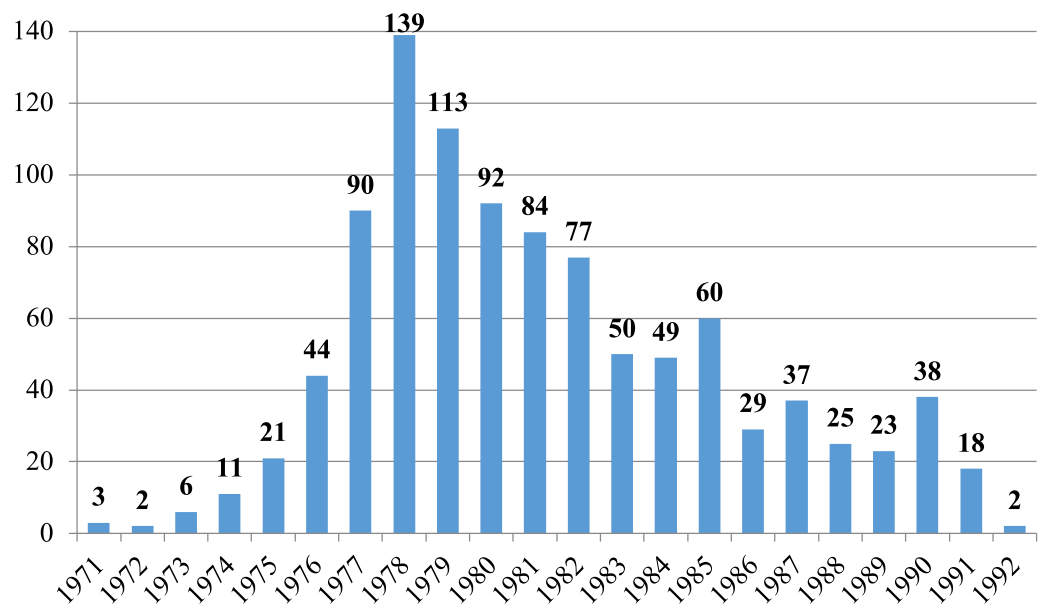

Fuente: elaboración propia a partir de Domínguez (1998: 33)

La condición clandestina de las organizaciones terroristas impide un estudio preciso sobre dimensión en términos cuantitativos y, por este motivo, "el cómputo del número de detenidos constituye habitualmente el procedimiento más sencillo para evaluar la militancia de ETA, aunque este sistema no permite diferenciar entre quienes forman parte del núcleo central y quienes constituyen el cinturón de colaboradores" (Domínguez, 1998: 36).

El crecimiento de la fracción de ETAm en los primeros compases de la transición permite acelerar sus acciones y añade una mayor dosis de presión política. Esta lógica exige una articulación ajustada a los márgenes de eficacia óptimos para reducir los costes inherentes a la lucha armada desarrollada por los grupos insurgentes. Las cifras sobre el establecimiento de comandos legales de la organización sugieren la existencia de un vigor social que facilita la práctica del ciclo violento en los primeros años del sistema parlamentario postfranquista. El interés de estas células reside en la relevancia que asumen para el fortalecimiento de ETA porque representan "la puerta natural de entrada en la organización terrorista de los nuevos militan- 
tes" (Domínguez, 1998: 188). Los grupos armados silencian sistemáticamente sus estructuras organizativas por razones obvias frente a la represión estatal y las únicas fuentes disponibles tienen un origen externo propiciado por las filtraciones policiales (Letamendía, 1997: 311)

El Gráfico 3 muestra la distribución cronológica anual de la constitución de comandos legales en Euskadi y evidencia el reclutamiento masivo concentrado en el trienio comprendido entre los años 1977-1979, ya que este período reúne el $41 \%$ de un total de 200 comandos establecidos hasta el año 1994. Su propósito esencial consiste en extender territorialmente sus núcleos armados y los 36 grupos legales creados en 1978 representan el máximo número de comandos formados anualmente. Este dato es relevante porque sugiere la incesante actividad de ETA en su lucha armada, ya que este ritmo certifica el nacimiento de un comando nuevo cada once días. Por consiguiente, el análisis constata el crecimiento de la organización en términos humanos y, al mismo tiempo, la capacidad para desarrollar una escalada de violencia durante los últimos años de la década de 1970.

Gráfico 3

Cifra de comandos legales en Euskadi (1977-1994)

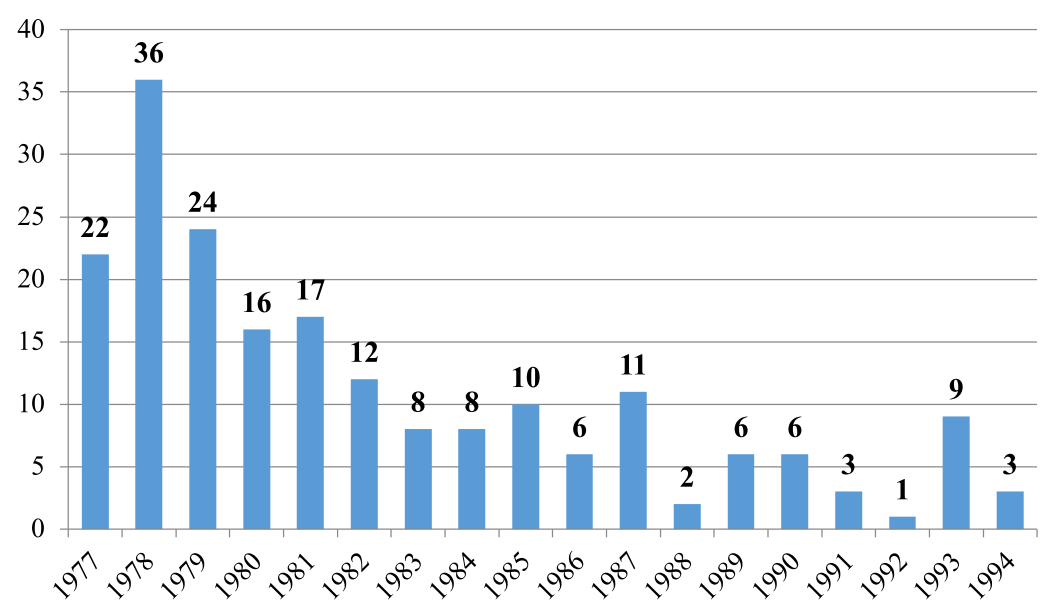

Fuente: elaboración propia a partir de Domínguez (1998: 191)

Los recursos movilizados están vertebrados por tres categorías de comandos: liberados, que desempeñan las acciones de mayor relevancia; legales, que están integrados 
por miembros desconocidos para las fuerzas de orden público y realizan múltiples funciones -enlaces, "buzones", información-; y, por último, los comandos de apoyo que proporcionan los medios necesarios para los integrantes del primer grupo (Letamendía, 1997: 311)

Los militantes reciben cursos de instrucción en los "santuarios" y estos cursos tienen una duración de dos semanas para proporcionar detalles sobre técnicas de combate, armamento, estrategias de comunicación y formación ideológica (Clark, 1984). Las estimaciones aportadas por fuentes procedentes de los servicios de inteligencia españoles consideran que la cifra de militantes de ETA asciende hasta medio millar de miembros y, a comienzos de los años ochenta, el teniente-general Casinello indica que ETAm está constituida por unos 200 efectivos armados divididos entre unos 20-30 comandos ilegales (Letamendía, 1997)

El indicador de los comandos legales de ETA conduce al examen de una práctica desarrollada por el grupo armado: los secuestros. Esta variable muestra la potencialidad de su estructura derivada del compromiso de los militantes vinculados con las acciones de la organización y la disponibilidad de unas infraestructuras materiales estables que permiten la operatividad de secuestros prolongados. El Gráfico 4 ilustra el número anual de secuestros perpetrados por ETA, y alguna de sus organizaciones afines, durante los años que transcurren entre 1970-1989. De nuevo, los datos reflejan una práctica significativamente concentrada entre los años 1978-1980, ya que un $45^{\prime} 34 \%$ del total de los 86 secuestros registrados está agrupado en este lapso temporal.

Asimismo, estas acciones representan nuevos cauces de financiación para ETA mediante la extorsión económica. En este sentido, en noviembre de 1988, el auto dictado por Carlos Bueren del Juzgado Central de Instrucción $n^{\circ} 1$ de la Audiencia Nacional indica que 1.1 millones de pesetas - unos 7 millones de euros, aproximadamente- procede de la extorsión sistematica realizada por el grupo armado entre los años 1975-1986 (Domínguez, 1998: 141)

Los criterios económicos motivan un 51'2 \% del total de los secuestros protagonizados por ETA durante todo el período, mientras que la presión política apenas representa un 16'3\% del total de los secuestros registrados (Llera y Leonisio, 2015: 151). El apogeo de esta práctica coercitiva coincide con los 13 y 18 secuestros realizados en los años consecutivos de 1979 y 1980. En efecto, estas acciones multiplican los recursos económicos de ETA y agilizan tanto la compra de armamento como la creación de infraestructuras dedicadas a ofrecer un soporte material que explica la posibilidad de mantener la lucha armada e incrementar su escalada de violencia política en la coyuntura estudiada. 
Gráfico 4

Número anual de secuestros cometidos por ETA y organizaciones afines (1970-1997) ${ }^{9}$

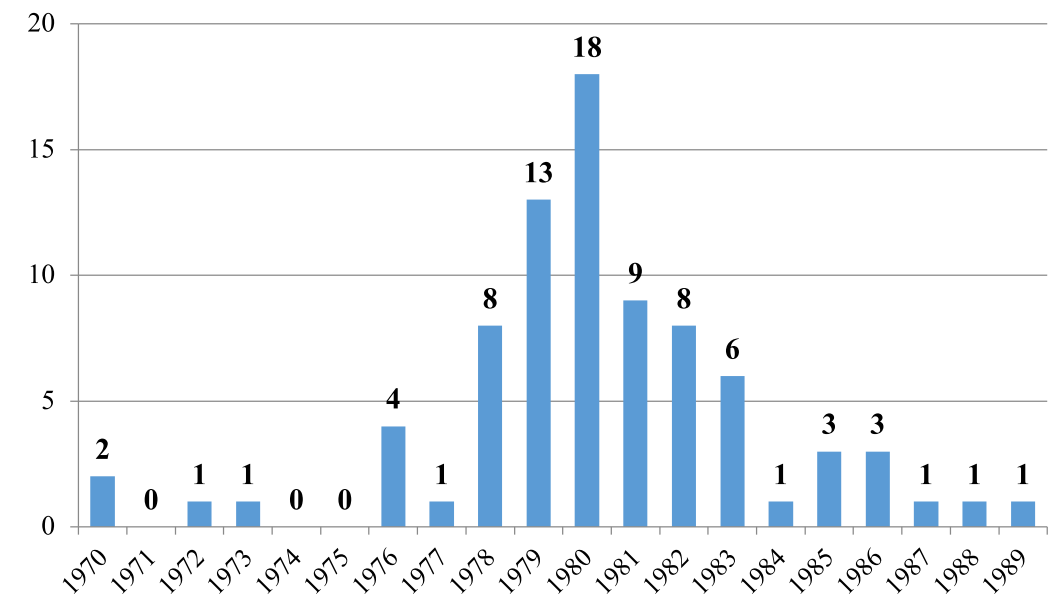

Fuente: elaboración propia a partir de Llera y Leonisio (2015: 146)

La tesis que invita a plantear un aumento en la práctica de la violencia dirigida a buscar una reacción social generalizada en virtud del apoyo social percibido por ETA suscita un enorme interés. Un ejemplo de este indicador es la difusión mediatizada a través de la propaganda elaborada por la propia organización, especialmente canalizada por los sucesivos boletines que publica Zutik (Fernández y López, 2012: 277). Además, los marcos de socialización política fortalecen las experiencias colectivas inscritas en entornos con connotaciones abertzales -fiestas patronales, núcleos familiares, cuadrillas, centros de trabajo- porque agilizan la construcción de una identidad compartida sumamente definida. El apoyo social difuso habilita un discurso legitimador que justifica el recurso de la opción armada para lograr unos objetivos centrados en la independencia política de Euskadi.

Los sentimientos que despierta ETA en función de las soluciones preferidas para la cuestión territorial vasca son significativas y las personas encuestadas que defienden la opción independentista muestra una respuesta "positiva" hacia el grupo armado en 1979, aunque esta actitud desciende desde un $52 \%$ hasta el $25 \%$ registrado en el año 1982 (Gráfico 5). En este sentido cobra importancia la exclusividad

9. Estos datos no contabilizan, por ejemplo, a las personas "retenidas" para robarles el coche, sino aquellos secuestros motivados por la extorsión económica y la presión para obtener demandas políticas, sociales y/o laborales. 
del ejercicio de la violencia política territorial, que busca una fuente legitimadora social y política (Letamendía, 1997: 312). Sin embargo, una explicación a este descenso remite a los efectos provocados por la continuidad de la violencia armada y su traducción inmediata en la polarización de las actitudes y los lazos de solidaridad, que dificultan la neutralidad y propician un endurecimiento de las fronteras que circunscriben a los grupos étnicos o ideológicos en conflicto (Crenshaw, 1983)

\section{Gráfico 5}

Comparativa sentimientos hacia ETA según la preferencia a la solución "problema regional" vasco, 1979-1982 (en \%)
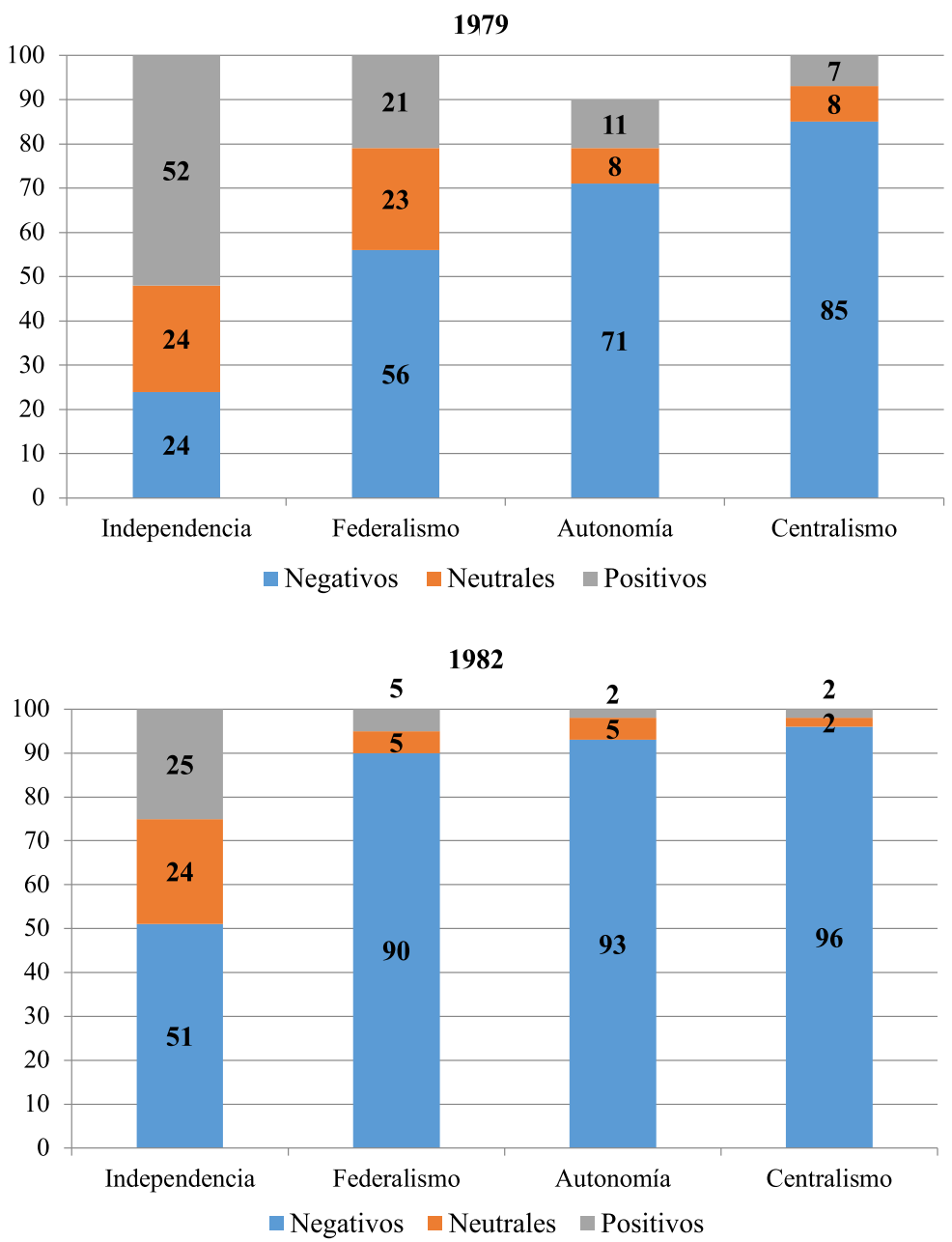

Fuente: elaboración propia a partir de Shabad (1986: 544) 
Las actitudes y opiniones públicas de la sociedad vasca muestran indicios de un velo de legitimidad, que fortalece la lectura analítica de ETA e impulsa su ofensiva a partir de 1979. Además, la represión protagonizada por las autoridades de la dictadura franquista no desaparece de Euskadi con la implantación del sistema democrático, mientras que el silencio es trasladado hacia otros ámbitos como consecuencia de la espiral producida por el terror y la consiguiente despolitización que conlleva el desplazamiento de numerosas familias (López, 2015). No obstante, el conjunto de estas singularidades no interrumpe la continuidad de la lucha armada que sostiene ETA porque permite simultáneamente la visibilidad de sus apoyos sociales y la interpretación del silencio como un estímulo cómplice.

El reducido tamaño de las movilizaciones manifestadas tras los atentados de ETA constituyen una fuente elocuente sobre el clima política que reina en el País Vasco durante los primeros compases de la transición y contrastan con las expresiones masivas convocadas por la izquierda abertzale en el mismo cuadro histórico (López, 2015: 55).

La referencia central para el Movimiento de Liberación Nacional Vasco (MLNV) es ETA y su crecimiento responde a la integración de diversas organizaciones sectoriales -sindicato, coaliciones electorales, grupos juveniles, asociaciones de mujeres, formaciones políticas- inscritas en la izquierda abertzale (Mata, 1993: 38-39). Su hegemonía responde a diversos factores sociopolíticos: la prioridad depositada en las cuestiones de identidad territorial, la capacidad para maniobrar en múltiples espacios sociales movilizados y la exclusividad del ejercicio de la violencia política en el territorio pretendidamente disputado.

La panorámica dibujada sobre la comunidad legitimadora de ETA también encuentra explicación en el cuadro socioeconómico que domina la década de 1970 y los primera mitad del siguiente decenio. La economía española está seriamente perjudicada por el desencadenamiento de una crisis con magnitudes globales, cuyo origen está situado en la primera mitad de la década de los años setenta. Esta coyuntura histórica coincide con el desmantelamiento inicial del paradigma keynesiano dominante durante la segunda posguerra y su principal efecto es, entre otras cuestiones, el crecimiento de los índices de desempleo. En los datos proporcionados por el Instituto Nacional de Estadística (INE), las tasas de paro relativas a la población activa española comprenden desde el 4'41\% correspondiente al tercer trimestre de 1976 hasta un 16'6 \% registrado en el último cuatrimestre de 1982. Un dato llamativo es el número de huelgas registrado en 1976, que asciende hasta un total de 40.179 paros laborales (Balfour, 1989: 149). En este escenario, la movilización nacionalista intensifica su presencia durante los primeros meses de 1976 
y su apogeo coincide, especialmente en el País Vasco y Cataluña, con numerosas huelgas obreras ${ }^{10}$. El desempleo, el terrorismo, la crisis económica y los precios ${ }^{11}$ son las cuestiones más preocupantes para la opinión pública española al finalizar la década de 1970, según los sondeos realizados por el Centro de Investigaciones Sociológicas (CIS, 1979).

\section{Conclusiones}

La incapacidad de las fuerzas que concurren a la cita democrática tras la experiencia de la dictadura franquista para imponer sus respectivos proyectos políticos desemboca en un proceso colmado de negociaciones, contradicciones y disputas. Las numerosas acciones violentas protagonizadas por grupos con inclinaciones ideológicas antagónicas añaden un elevado grado de tensión a un escenario caracterizado por la desmovilización paralela al avance democratizador y el clima de incertidumbre inherente a los procesos de transición política. ETA logra capitalizar las ofensivas violentas dirigidas a frenar el apuntalamiento del sistema constitucional e imponer sus reivindicaciones en torno a las reivindicaciones independentistas del País Vasco.

Las escisiones internas detectadas en el grupo armado no impiden la escalada de violencia desencadenada por ETA en su intento por satisfacer sus expectativas políticas. No obstante, la aprobación del Estatuto de Autonomía en 1979 evidencia un segundo distanciamiento protagonizado por las diferentes opciones nacionalistas y que tiene como extremos la moderada apuesta parlamentaria del PNV y la radicalidad de ETA, junto con sus grupos afines.

La decisión de ETA para impulsar una ofensiva motivada por su crecimiento interno, cuya visibilidad es apreciable en la progresiva creación de comandos y la capacidad material derivada de algunas prácticas extorsionadoras -por ejemplo, los secuestros o el cobro de una tasa monetaria para financiar sus acciones-, también entronca con la desmovilización progresiva originada por la respuesta del centro político en forma de medidas democratizadoras.

El dilema de ETA transcurre entre la ruta política aportada por el Estatuto para profundizar en el camino hacia la independencia del País Vasco o el recurso a la lucha armada para frenar la consolidación de un proceso institucional democrático

10. En 1975, el año de mayor militancia obrera bajo el franquismo, las movilizaciones suman 3.156 huelgas laborales; sin embargo, esta cifra aumenta hasta las 17.731 huelgas registradas durante el primer trimestre de 1976 (Maravall y Santamaría, 1985: 92).

11. En el caso particular del índice de inflación anual, los datos muestran una tendencia creciente que desborda la década de los años setenta, cuyo apogeo corresponde al 26’3 \% registrado en el año 1977. 
contradictorio con los propósitos de la organización. El estancamiento de la apuesta parlamentaria evidenciada por los resultados electorales y la baja representatividad obtenida por las candidaturas rupturistas inclinan la balanza a favor de la continuidad de la práctica violenta iniciada en los últimos compases de la dictadura.

La comunidad legitimadora desempeña un papel fundamental en la prolongada actividad armada de ETA, que está fundamentada en los principios teóricos de la guerra revolucionaria y favorecida, al menos inicialmente, por la desacertada intervención de las fuerzas represivas estatales. Un buen ejemplo de la errática actuación policial son los sucesos registrados en la movilización obrera celebrada en Vitoria durante el mes de marzo de 1976, cuyo balance final asciende a cinco fallecidos y más de un centenar de heridos.

Por último, la violencia política ejercida por ETA está concentrada en la segunda mitad de la década de 1970 y los primeros años del siguiente decenio. Sin embargo, la prolongación de su estrategia basada en forzar la insurrección popular mediante acciones violentas muestra un agotamiento entre su comunidad legitimadora. El desarrollo y la paulatina consolidación del modelo democrático permiten al sistema político español inscribir su trayectoria en la lógica que domina la dinámica continental mediante la solicitud de adhesión al proyecto económico europeo, cuya formalización culmina a mediados de la década de 1980, así como la reafirmación de permanecer en la esfera de seguridad del Tratado Atlántico Norte y el inicio de una estrecha colaboración con Francia en la lucha contra el terrorismo.

\section{Bibliografía}

ARANZADI, J. (1994) "Violencia etarra y etnicidad", en Ayer. Violencia y política en España, 13, 189-209

ARÓSTEGUI, J. (1994) “Violencia, sociedad y política: la definición de la violencia”, Ayer. Violencia y política en España, 13, 17-55

BABY, S. (2018) El mito de la transición pacífica. Violencia y política en España (19751982), Madrid: Akal

BALFOUR, Sebastian (1989) Dictatorship, Workers and the City, Oxford, Clarendon Press

CIS (1979) Estudio 1205. Barómetro de diciembre

CLARK, R. (1984) The Basque Insurgents: ETA 1952-1980, Wisconsin: University Wisconsin Press

COVERDALE, J. F. (1979) The political transformation of Spain after Franco, New York: Praeger 
CRENSHAW, Martha (1981) “The causes of terrorism”, Comparative Politics, 13 (4), 379-399

CRENSHAW, M. (comp.) (1983) Terrorism, legitimacy and power. The consequences of political violence, Connecticut: Wesleyan University Press

CRENSHAW, Martha (1987) “Theories of terrorism: Instrumental and organizational approaches", Journal of Strategic Studies, 10 (4), 13-31

CRENSHAW, M. (1994) "La lógica del terrorismo: comportamiento terrorista como producto de una elección estratégica”, en W. REICH (comp.) Orígenes del terrorismo. Psicología, ideología, teología, estados mentales, Barcelona: Pomares, 17-35

DELLA PORTA, Donatella (1996) "Lógica de las organizaciones clandestinas: un análisis comparado en Italia y Alemania”, Sistema. Revista de Ciencias Sociales, 132-133, 231-257

DOMÍNGUEZ, F. (1998): ETA: estrategia organizativa y actuaciones, 1978-1992, Bilbao, Universidad del País Vasco

DOUGLASS, William y Joseba ZULAIKA (1990) "On the Interpretation of terrorist violence: ETA and the Basque political process", Comparative Studies in Society and History, 32 (2), 238-257

DRAKE, C. J. M. (1998): “The Role of Ideology in Terrorists' Target Selection”, Terrorism and Political Violence, 10 (2), 53-85

FERNÁNDEZ, Gaizka (2013) "Los nacionalismos radicales de la periferia durante la Transición española”, en R. QUIROSA-CHEYROUZE (coord.) Los partidos en la Transición. Las organizaciones políticas en la construcción de la democracia española, Madrid: Biblioteca Nueva, 345-358

FERNÁNDEZ, Gaizka y Raúl LÓPEZ (2012) Sangre, votos, manifestaciones: ETA y el nacionalismo vasco radical (1958-2011), Madrid: Tecnos

GURRUTXAGA, A. (2005): “Transición política en España: Estado y nacionalismo vasco", en C. H. WAISMAN, R. REIN y A. GURRUTXAGA (comps.) Transiciones de la dictadura a la democracia: los casos de España y América Latina, Bilbao: Universidad del País Vasco, 141-166

HOFFMAN, Aaron M. (2010) "Voice and silence: Why groups take credit for acts of terror", Journal of Peace Research, 47 (5), 615-626

HUNTINGTON, S. (1994) La tercera ola. La democratización a finales del siglo XX, Barcelona: Paidós

Instituto Nacional de Estadística

JÁUREGUI, G. (2006) "ETA: orígenes y evolución ideológica y política”, en A. ELORZA, (coord.), La historia de ETA, Madrid: Temas de Hoy, 173-270 
LARANA, E. (1999) La construcción de los movimientos sociales, Madrid: Alianza LETAMENDÍA, F. (1997) Juego de espejos. Conflictos nacionales centro-periferia, Madrid: Trotta

LETAMENDÍA, F. (2011) "La izquierda abertzale en la pre-transición (1974 - junio 1977)”, Viento Sur, (115), 87-94

LINZ, J. J. (1993) "Innovative Leadership in the Transition to Democracy and a New Democracy. The Case of Spain”, en G. SHEFFER (comp.) Innovative Leaders and International Politics, New York: State University of New York Press, 127-154

LÓPEZ, R. (2015): Informe Foronda. Los efectos del terrorismo en la sociedad vasca, Madrid, Catarata

LLERA, Francisco J. (1984) "El sistema de partidos vascos: distancia ideológica y legitimación política”, en Revista Española de Investigaciones Sociológicas, 28, 171-206

LLERA, Francisco J. (1998): "Pluralismo y gobernabilidad en Euskadi (1980-1994)", en M. ALCÁNTARA y A. MARTÍNEZ (Coords.), Las elecciones autonómicas en España, 1980-1997, Madrid, Centro de Investigaciones Sociológicas, pp. 413-444

LLERA, Francisco J. y Rafael LEONISIO (2015) "Los secuestros de ETA y sus organizaciones afines, 1970-1997”, Revista Española de Ciencia Política, 37, 141 160

MARAVALL, José María y Julián SANTAMARÍA (1985) "Crisis del franquismo, transición política y consolidación de la democracia en España”, Sistema. Revista de Ciencias Sociales (68-69), 79-130

MARAVALL, J. M. y J. SANTAMARÍA (1989) "El cambio político en España y las perspectivas de la democracia”, en O’DONNELL, G., P. C. SCHMITTER y L. WHITEHEAD (comps.) Transiciones desde un gobierno autoritario. Vol. 1. Europa meridional, Buenos Aires: Paidós, 112-164

Ministerio del Interior

MATA, J. M. (1993): El nacionalismo vasco radical: discurso, organización y expresiones, Bilbao, Universidad del País Vasco

O’DONNELL, G. y P. C. SCHMITTER (1988): Transiciones desde un gobierno autoritario. Vol. 4. Conclusiones tentativas sobre las democracias inciertas, Buenos Aires: Paidós

PÉREZ LEDESMA, M. (1994) Cultura y movilización en la España Contemporánea, Madrid: Alianza

PRIDHAM, G. (1995) Transitions to Democracy. Comparative Perspectives form Southern Europe, Latin America and Eastern Europe, Aldershot: Dartmouth Publishing 
PRZEWORSKI, A. (1988): "Algunos problemas en el estudio de la transición hacia la democracia”, en O'DONNELL, G., P. C. SCHMITTER y L. WHITEHEAD (comps.) Transiciones desde un gobierno autoritario. Vol. 3. Perspectivas comparadas, Buenos Aires: Paidós, 79-104

PRZEWORSKI, A. (1991) Democracy and the market. Political and economic reforms in Eastern Europe and Latin America, Cambridge: Cambridge University Press

SÁNCHEZ-CUENCA, I. y P. AGUILAR (2009) "Terrorist Violence and Popular Mobilization. The case of the Spanish Transition to Democracy", Politics \& Society, 37 (3), 428-453

SHABAD, Goldie (1986): “Las elecciones de 1982 y las autonomías", en Juan J. LINZ, y José R. MONTERO (eds.) Crisis y cambio: electores y partidos en la España de los años ochenta, Madrid: Centro de Estudios Constitucionales, 525-585

SOTO, Á. (2005) Transición y cambio en España (1975-1996), Madrid: Alianza SULLIVAN, J. (1988), El nacionalismo vasco radical, 1959-1986, Madrid: Alianza UNZUETA, P. (1997) Terrorismo. ETA y el problema vasco, Barcelona: Destino WILKINSON, Paul (1986) Terrorism and the Liberal State, Londres: MacMillan 
